\title{
Inter- and intra-tree variability in quality of figs. Influence of altitude, leaf area and fruit position in the canopy
}

\author{
Mehdi Trad $^{\mathrm{a}, *}$, Badii Gaaliche ${ }^{\mathrm{a}}$, Catherine M.G.C. Renard ${ }^{\mathrm{b}}$, Messaoud Mars ${ }^{\mathrm{a}}$ \\ a UR Agrobiodiversity, High Agronomic Institute, IRESA/ University of Sousse, 4042 Chott-Mariem, Tunisia \\ ${ }^{\mathrm{b}}$ INRA, Université d'Avignon et des pays du Vaucluse, UMR408 SQPOV, F-84000 Avignon, France
}

Keywords:

Ficus carica

Firmness

TSS:TA ratio

Location

Shade

Canopy management

\begin{abstract}
A B S T R A C T
Shading effect on quality of fig (Ficus carica L.) is noteworthy within the tree. Leaf area and canopy density enhanced shade conditions and altered microclimate inside 'Bouhouli' fig tree. With leaf area index (LAI) of about 3.3 there was a tendency to have smaller, firmer and lighter skin coloured fruit inside the canopy. Altitude level had a little influence on quality of 'Bouhouli' figs. Though, fruits from mountainous zone of 'Djebba' ripened earlier and were heavier and less acid than fruits from nearby plain of 'Thibar'. Position of the fruit in the canopy significantly affected fruit firmness, titratable acidity (TA) and TSS:TA ratio $(p<0.01)$. There were greater fruit loads with soften receptacle and lower acidity in the outside canopy positions than in the inside positions. No differences exist in dry matter (18.7\%) and soluble solids content (18.3\%) between light exposed and shaded fruits. Yet, TSS:TA ratio was higher in figs harvested from the periphery. Sugar and organic acid concentrations were little influenced by fruit position in altitude or in the tree. Glucose, fructose and sucrose showed the same proportions 0.47 , 0.38 and 0.15 , respectively, inside and outside the canopy. Citric acid, the predominant organic acid in figs, had comparable concentrations in fruit from inner and outer part of the tree. Citric acid levels were though different $(p<0.05)$ between fruits from the two locations $(1.95$ mequiv./100g FW in the plain versus 2.80 mequiv./100 g FW in the mountain). Temperature was positively correlated with fresh weight $\left(r=0.74^{*}\right)$ but negatively correlated with firmness and titratable acidity $\left(r=-0.91^{* *}\right)$. High temperature degrees during maturity enhance fruit enlargement and softening and reduce acidity of fig juice. Growing figs in mountainous and uneven zones with high altitude remains profitable to farmers living these areas. To improve light penetration into the foliage, summer pruning, leaf removal and shoot vigour control, little practiced in fig species, are recommended close to maturity and lead to homogeneous quality of fig crops.
\end{abstract}

\section{Introduction}

In woody plants, bearing fruit may result on heterogeneity in final quality sometimes more perceptible between fruits within the same tree than that from different trees. This problem observed in many fruit species (apple, apricot, citrus, etc.) may be an obstacle for crop marketing (Mars and Marrakchi, 2000). Inter- and intra-tree variability was attributed to many factors such as the rootstock used (Lipe and Perry, 1988), growing techniques: pruning, fruit thinning (Fellahi and Simons, 1993) or the microclimate generated by the amount of light intercepted by the canopy, temperature or

Abbreviations: LA, leaf area; LAI, leaf area index; $\mathrm{RH}$, relative humidity; TSS, total soluble solids; TA, titratable acidity; FW, fresh weight; DM, dry matter; SD, standard deviations; ANOVA, analysis of variance; SPSS, statistical package for social sciences; $\mathrm{cv}$, cultivar.

* Corresponding author. Tel.: +216 73327544; fax: +216 73327591.

E-mail address: mh.trad@yahoo.com (M. Trad). humidity (Erez and Flore, 1986; Audergon et al., 1991; Mars et al., 1994).

Crop composition and quality is determined by sunlight distribution within the canopy, with shade reducing fruit quality. This is a general issue among perennial fruit crops and has been reported for apple, citrus, peach, cherry, kiwifruit and red raspberry (Palmer, 1989). In figs, Ficus carica, the phenomenon is even more accentuated since the species develops a highly dense canopy marked by a large leaf area which could represent in some cases a natural sunshade for the fruit. Several parameters are considered to be influenced by solar radiation, including fruit size, flesh firmness, soluble solids, anthocyanin and starch content, acidity, $\mathrm{pH}$ and dry matter (Erez and Flore, 1986; Kliewer and Smart, 1989). High sugar levels, an appropriate sugar/acid ratio and adequate flesh firmness are among most important characteristics of highquality figs (Çaliskan and Polat, 2008; Trad et al., 2012). Berries, known to be rich in organic acids (Koyuncu, 2004), are influenced by environmental conditions. Mulberry, belonging to the Moraceae family, had not the same chemical composition in fruits from 
Version définitive du manuscrit publiée dans / Final version of the manuscript published in :

Scientia Horticulturae (2013), Vol. 162, p. 4954, DOI: 10.1016/j.scienta.2013.07.032

Journal homepage: http://www.journals.elsevier.com/scientia-horticulturae

different growing areas (Ercisli and Orhan, 2007). In black mulberry (Morus nigra L.), the amount of total organic acids was dependant on the geographical origin. Especially differences in the climate are likely to explain these distinctions (Koyuncu, 2004).

Distribution of fruits within the fig tree underlines heterogeneity in visual aspects of quality between figs underneath the foliage and those from the periphery. This could disrupt harvest campaign and impede product marketing. In our observations, there was a variation on fruit quality and maturity between figs (cv. 'Bouhouli') harvested from the plain of 'Thibar' and fruits gathered from mountainous region of 'Djebba'. Altitude seems to affect quality of figs. In Tunisia, the mountainous location of 'Djebba' represents a particular agro-ecological site for fig crop cultivation with a substantial genetic diversity. Little attention was paid to the climate prevailing during maturity of figs in relation with situation of the fruit as well as in distant orchards or in the same tree. Fruit quality is highly influenced by environmental conditions, climate and orchard management and may change from year to year (Inglese et al., 2002; Ochoa et al., 2006).

The aim of this study was to analyze the effect of altitude, proximate environment and fruit position in the canopy on morphological and chemical aspects of quality in figs (cv. 'Bouhouli'). The results given below could enable fig growers to set up and manage their orchard and to manipulate the fig tree to produce a higher yield of top quality fruit at harvest time since tree training and pruning skills in general remain not much controlled.

\section{Materials and methods}

\subsection{Plant material}

Figs from cultivar 'Bouhouli' (dark skinned fruit) were selected for this study. Fruits were gathered from an extended area of fig production: 'Thibar' in the Northwest of Tunisia (altitude, $327 \mathrm{~m}$; latitude, $36^{\circ} 31^{\prime} \mathrm{N}$; longitude, $9^{\circ} 5^{\prime} \mathrm{E}$ ) distinguished by a sub-humid climate, annual mean temperature of $20^{\circ} \mathrm{C}$ and annual rainfall of $600 \mathrm{~mm}$. Fig trees produced by cutting were planted in 1991 with $7 \mathrm{~m} \times 7 \mathrm{~m}$ spacing and shaped under goblet.

The influence of altitude on fruit quality was evaluated in figs from mountainous zone of 'Djebba' (altitude, $800 \mathrm{~m}$; latitude, $36^{\circ} 40^{\prime} \mathrm{N}$; longitude, $9^{\circ} 0^{\prime} \mathrm{E}$ ) with comparison to fruits harvested from the plain of 'Thibar'. 'Djebba', situated in a sloping field, is characterized by a sub-humid climate. Annual means temperature is set around $20^{\circ} \mathrm{C}$. Thermal amplitude is about $16.5^{\circ} \mathrm{C}$ in summer and $8{ }^{\circ} \mathrm{C}$ in winter. This zone receives annual rain of about $600 \mathrm{~mm}$. Three trees from each location were selected for fruit sampling. From each tree, 20 fruits were picked at full maturity. The same cultivation techniques, especially irrigation and caprification, were applied in two.

\subsection{Leaf area and fruit environment assessment}

Leaf area (LA) determination was conducted on three trees from cultivar 'Bouhouli' in the region of 'Thibar'. Total canopies for each tree as well as total leaf number from one canopy already selected were counted. From the same canopy, 25 leaves were picked. Leaves selected were those reaching their final size and bearing fruits underneath (Hunt, 1990; Can, 2008). Leaf area was measured in the laboratory using a planimeter (Type AM 200, ADC Bioscientific Ltd., Hoddesdon, Herts, England). Determination of leaf area index (LAI) required the measurement of the total leaf area of the canopy and the total ground area upon which it stands (Hunt, 1990). The same trees were selected to monitor the internal and external microclimate surrounding fig fruit in the tree. Thermo-hygrometers (Type 46618 Badget Packolabel Systems, Delhi, India) were simultaneously installed inside and outside the canopy $(50 \mathrm{~cm}$ from the tip of the canopy) (Mars et al., 1994). Three measurements of temperature and relative humidity $(\mathrm{RH})$ were taken daily starting from the last week before harvest (beginning of fruit veraison) in the time period between $11.00 \mathrm{~h}$ and $13.00 \mathrm{~h}$ (most enlightened phase of the day).

\subsection{Fruit sampling}

Twenty fruits per tree (10 from the periphery and 10 from the inside of the tree) were picked to constitute a final sample of 60 figs for each altitude. Fruits were harvested in late august during two cropping seasons, 2009 and 2010. The fruits were randomly picked, fully ripe, from the all sides and immediately stored until analysis. Samples kept first at $-20^{\circ} \mathrm{C}$, were then ground in liquid nitrogen using a basic analytical mill (IKA ${ }^{\circledR} \mathrm{A} 11$. Germany) and the powder obtained was stored at $-80^{\circ} \mathrm{C}$ for chemical analysis.

\subsection{Fruit analysis}

\subsubsection{Morphological and physico-chemical description}

Main descriptors for fig fruit (IPGRI and CIHEAM, 2003) were assessed for the cultivar 'Bouhouli'. Parameters measured were: fruit size, shape, length, neck length, width and ostiole width. Firmness was measured using the durofel (durometer Duro10, SETOP GIRAUD Technology, Cavaillon, France) and external fruit colour was determined according to IPGRI scale (IPGRI and CIHEAM, 2003). Total soluble solids (TSS) was determined using a hand-held digital refractometer (PR-101 ATAGO, Norfolk, VA) and expressed in percent (\%) at $20^{\circ} \mathrm{C}$. titratable acidity (TA), expressed as mequiv. $/ 100 \mathrm{~g}$ FW, was determined by titrating fig juice with $0.1 \mathrm{M} \mathrm{NaOH}$. Four grams of fresh powder of the fruit were dried $\left(70^{\circ} \mathrm{C}\right.$ for $\left.96 \mathrm{~h}\right)$ and removed to be weighed again for dry matter (DM) determination.

\subsubsection{Sugars and organic acids determination}

From each sample, $5 \mathrm{~g}$ of frozen fig powder were mixed with $20 \mathrm{ml}$ ultra pure water. Samples were ground with an ultraturrax T25 equipment (Ika Labortechnik, Staufen, Germany) to obtain slurry. The mixture was homogenized and then centrifuged for $5 \mathrm{~min}$ at $4{ }^{\circ} \mathrm{C}(9000 \mathrm{rpm})$. Samples were then filtered and the supernatant recovered. The extracts were kept at $-20^{\circ} \mathrm{C}$ until analysis. Glucose, fructose and sucrose, malic and citric acids were quantified using enzymatic methods with kits for food analysis (Boehringer Mannheim Co., Mannhein, Germany) and expressed in g/100 g of fresh weight for sugars and mequiv./100 g FW for acids. Spectrophotometric measurements were performed using an automatic analyser (BM-704, Hitachi, Tokyo, Japan).

\subsection{Statistics}

Results presented are as means $(N=3) \pm$ standard deviations (SD). Environment effects on quality of figs were carried out in triplicate from samples harvested over 2 years. Data were subject to one-way analysis of variance (ANOVA). Significant differences were assessed with Duncan's multiple range test $(p<0.05)$. Pearson's correlation coefficients were estimated between climatic factors and quality parameters of the fruit and correlation plot was displayed in the circle of correlations. Statistics were performed using PC software package SPSS (version 13.0; SPSS Inc.).

\section{Results and discussion}

\subsection{Effect of altitude on quality of figs}

Data related to quality of figs under the influence of altitude were displayed in Table 1. Figs harvested from mountainous 
Version définitive du manuscrit publiée dans / Final version of the manuscript published in :

Scientia Horticulturae (2013), Vol. 162, p. 4954, DOI: 10.1016/j.scienta.2013.07.032

Journal homepage: http://www.journals.elsevier.com/scientia-horticulturae

Table 1

Effect of altitude and position of the fruit in the canopy on sugars (g/100 g FW), organic acids (mequiv./100 g FW) and physico-chemical parameters of 'Bouhouli' figs.

\begin{tabular}{|c|c|c|c|c|c|c|}
\hline & \multicolumn{6}{|l|}{ ‘Bouhouli’ figs } \\
\hline & Plain (327 m) & Mountain (800 m) & $F$-value & Underneath & Periphery & $F$-value \\
\hline Fresh weight (g) & $55 \pm 4$ & $63 \pm 4$ & 5.95 & $61 \pm 5$ & $64 \pm 2$ & 0.77 \\
\hline Firmness (df) & $17 \pm 1$ & $17 \pm 1$ & 0.25 & $18 \pm 1$ & $16 \pm 1$ & $32.00^{* *}$ \\
\hline TSS (\%) & $17.6 \pm 0.9$ & $18.1 \pm 0.9$ & 0.34 & $17.7 \pm 0.8$ & $18.3 \pm 1.1$ & 0.56 \\
\hline $\mathrm{TA}(\%)$ & $0.27 \pm 0.01$ & $0.23 \pm 0.02$ & $9.60^{*}$ & $0.29 \pm 0.02$ & $0.22 \pm 0.01$ & $36.75^{* *}$ \\
\hline TSS:TA & $65 \pm 5$ & $79 \pm 5$ & $11.44^{*}$ & $61 \pm 2$ & $83 \pm 5$ & $47.03^{* *}$ \\
\hline Dry weight (\%) & $19.7 \pm 2.5$ & $20.0 \pm 2.0$ & 0.03 & $18.7 \pm 0.0$ & $18.7 \pm 0.0$ & 0.00 \\
\hline Skin colour ${ }^{\mathrm{a}}$ & Purple green & Purple green & - & Purple green & Purple green & - \\
\hline \multicolumn{7}{|l|}{ Sugars } \\
\hline Glucose & $6.35 \pm 0.53$ & $6.44 \pm 1.44$ & 0.02 & $6.06 \pm 1.00$ & $6.24 \pm 1.00$ & 0.05 \\
\hline Fructose & $4.77 \pm 0.43$ & $5.06 \pm 0.84$ & 0.29 & $4.84 \pm 0.68$ & $4.95 \pm 0.77$ & 0.03 \\
\hline Sucrose & $1.97 \pm 0.30$ & $1.98 \pm 0.27$ & 0.00 & $1.98 \pm 0.14$ & $1.97 \pm 0.49$ & 0.00 \\
\hline \multicolumn{7}{|l|}{ Organic acids } \\
\hline Citric acid & $1.95 \pm 0.57$ & $2.80 \pm 0.13$ & $6.39^{*}$ & $2.85 \pm 0.48$ & $2.75 \pm 0.17$ & 0.10 \\
\hline Malic acid & $1.31 \pm 0.16$ & $1.32 \pm 0.50$ & 0.00 & $1.67 \pm 0.25$ & $1.27 \pm 0.52$ & 1.46 \\
\hline
\end{tabular}

TSS, total soluble solids; TA, titratable acidity; df, durofel. Numeric values displayed are means $\pm \mathrm{SD}(N=3)$.

a Descriptors for figs (IPGRI and CIHEAM, 2003).

Significant level $(p<0.05)$.

${ }^{* *}$ High significant level $(p<0.01)$.

'Djebba' were larger, bulkier and less acid than fruits harvested from the plain of 'Thibar'. In 'Djebba', figs ripened earlier (about 1 week earlier) with a high TSS:TA ratio reflecting a full mature receptacle. Firmness as well as total soluble solids showed almost the same values. No change was observed in external appearance and skin colour (purple green) of the fruit from the two regions. Dry matter content (20\% FW) showed the same values in fruits from the two altitudes. Elevation significantly $(p<0.05)$ reduced acidity of the juice and enhanced ripening process (TSS:TA). Our results are in agreement with those found in cactus pear fruit grown in different locations of South Africa (De Wit et al., 2010). These authors showed that elevation was responsible of low rated acidity and $\mathrm{pH}$ of cactus pear juice in several cultivars. Similarly, pomegranates cultivated in low altitude were more acids than fruits harvested from elevated zone leading to delayed maturity (Shulman et al., 1984). Olive tree growing in two different altitude levels ( $100 \mathrm{~m}$ and $800 \mathrm{~m}$ ) in Greece produced low acid oil for both locations with higher the oil obtained from fruits from $100 \mathrm{~m}$ (Mousa et al., 1999).

Sugar is basic ingredient of fruit quality and a source of carbohydrates. Figs are very rich fruit in sugars, in particular, in glucose and fructose (Melgarejo et al., 2003; Trad et al., 2012). Altitude had no incidence on sugars concentration in figs. Fruits originated from mountainous 'Djebba' produced $13.5 \mathrm{~g} / 100 \mathrm{~g}$ FW versus $13.1 \mathrm{~g} / 100 \mathrm{~g}$ FW in fruits harvested from 'Thibar' and glucose, the main component, represented $47.7 \%$ and $48.5 \%$, respectively, in fruits from mountain and nearby plain. Levels of fructose and sucrose were the same in fruits gathered from the two regions (Table 1). Cactus pear growing in low altitude produced high fructose compared to fruits picked from high locations. Glucose rates did not differ in fruits from different origins (De Wit et al., 2010).

Organic acid concentrations in figs were different between the two locations. Variations concerned citric acid and elevation was responsible of increasing levels of citrate in the fruit $(p<0.05)$. Citric acid, the predominant organic acid in figs, reached 2.80 mequiv./100 g FW in samples from 'Djebba' against 1.95 mequiv./100 g FW in fruits from the plain of 'Thibar'. Malic acid concentrations showed similar values between the two localities and elevation had no influence on malic acid content in the fruit. In olives (cv. Gemlik), levels of malic, oxalic and succinic acids changed with altitude (Arslan and Ozcan, 2011). Organic acid rates in the fruit are sensitive to altitude level. In figs, citric acid was the only organic acid influenced by elevation in altitude.
Contrary to published work (Kulina et al., 2002), F. carica can be cultivated in high altitude $(800 \mathrm{~m}$ in sub-humid conditions of Tunisia) with no peril on yield and final quality of the fruit. Elevation in altitude causes a net decline in variance between day and night temperatures and relatively large differences between day and night temperatures are characteristic of inland growing areas. This modifies the global climate surrounding fig tree in the mountain during maturity. Claims have been made that fluctuations in temperature range have a marked effect on physiological processes (Ochoa et al., 2009; De Wit et al., 2010). Hence, there is certainly a link between quality traits of figs and summer air humidity and summer temperature. As irrigation and other cultivation practices do not differ greatly in these two regions, taste and nutritional properties of the fruit are controlled by climatic factors.

\subsection{Effect of the fruit position in the canopy on quality of figs}

\subsubsection{Leaf area (LA), leaf area index (LAI) and proximate environment}

Cultivar 'Bouhouli' is distinguished by an important leaf area and the general appreciation of the foliage in fig tree indicates a medium sized leaf with high leaf area index (LAI) (IPGRI and CIHEAM, 2003). LAI is highly correlated with photosynthesis, evapotranspiration, productivity and yield (McPherson and Peper, 1998). In fig species, high LAI value is responsible of increasing sugar rates and dry matter content in the fruit (Can, 2008; Trad et al., 2012). However, high LAI value can be indicator of canopy density and shading degree within the tree. In kiwifruit, an LAI of 3 is typical of well managed orchard, whereas 5.5 indicate an extremely dense canopy (Snelgar et al., 1998). High values of LAI were found to decrease mean fruit size in grapes at an amount of $5.8 \mathrm{~g}$ per LAI. The phenomenon is more accentuated when crop loads per shoot were high (Snelgar and Martin, 1997). Fig is endowed with large leaf area and dense canopy which directly affect environment inside the tree and prompt shade conditions in the canopy. The combination of high LAI (3.3) and important leaf area $\left(379 \mathrm{~cm}^{2}\right)$ results on low light levels under the canopy and intensely shaded fruit. There is undoubtedly a relationship between leaf area and fruit development in figs with net influence on fruit quality. Light deprivation inside the canopy may cause depletion in quality of figs as demonstrated in grapevine (Smart et al., 1990) and kiwifruit (Snelgar et al., 1998). Shade conditions may alter quality of the fruit within the canopy with important physiological implications for leaves and fruit in shade conditions. 
Version définitive du manuscrit publiée dans / Final version of the manuscript published in :

Scientia Horticulturae (2013), Vol. 162, p. 4954, DOI: 10.1016/j.scienta.2013.07.032

Journal homepage: http://www.journals.elsevier.com/scientia-horticulturae

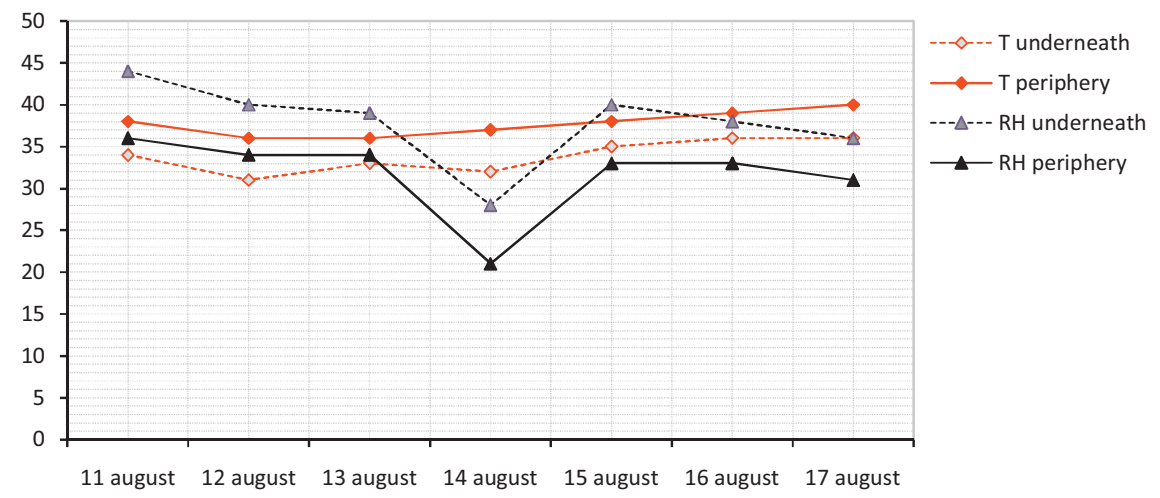

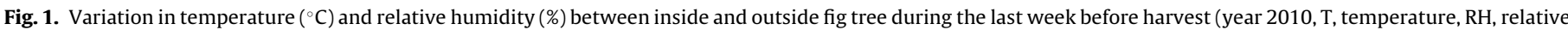
humidity). August 11: beginning of veraison. August 17: beginning of maturity.

Monitoring of the microclimate inside fig tree during the last week before harvest showed significant differences between interior and external environment of the canopy (Fig. 1). Relative humidity increased from $32 \%$ outside to $38 \%$ inside the tree $(p<0.05)$. Whereas, a decline in temperature values was registered from the periphery to underneath with temperature degrees falling from 38 to $34^{\circ} \mathrm{C}$ inside the canopy $(p<0.01)$. Dense foliage in fig tree contributed to change in environmental conditions between inside and outside. Proximate environment of the fruit was not the same from periphery to underneath. Temperature and relative humidity changed significantly with a remarkable light deprivation in the core of the tree. From the veraison to full maturity, the last week before harvest is determinant in development and ripening process. Most of the physiological events take place during the last period prior to harvest (Vidaud, 1997). Yet, data from Erez and Flore (1986) and Loreti et al. (1993) for relative humidity and temperature, respectively, demonstrate that the role played by these two factors is negligible.

\subsubsection{Quality of figs related to position of the fruit in the canopy}

Figs harvested from periphery of the tree were heavier, sweeter and more mature than those picked from underneath the canopy (Table 1). Discrepancy was especially observed in fruit firmness and titratable acidity values $(p<0.01)$. Figs directly exposed to sunlight were softer and less acid at harvest. Small differences were noticed in fresh and dry weight between the internal and external part of the tree although the major part of crop load exist in the periphery of the canopy. Total soluble solid (TSS) concentrations were almost similar in fruits from both outside $(18.3 \%)$ and inside $(17.7 \%)$ the tree. However, TSS:TA ratio was higher $(p<0.01)$ in figs picked from the periphery (83) compared to fruits from underneath (61) leading to a delay in maturity of shaded fruit.

Concentrations in glucose, fructose and sucrose were almost similar in figs from outside and inside the tree. As well for sugars, concentrations in organic acids did not differed between external and internal fruit (Table 1). Concentrations in glucose, predominant sugar in figs, exceeded $6 \mathrm{~g} / 100 \mathrm{~g}$ FW depends on the position of the fruit in the branch. The high values of LAI clearly contribute to increase in levels of sugar in the fruit. Citric acid, the main organic acid in figs, was slightly more concentrated in fruit situated underneath the foliage (2.85 mequiv./100g FW). Disproportion was especially observed in concentration of malic acid. Shaded fruit was richer in malate than the light exposed (1.67 and 1.27 mequiv./100 g FW respectively). In figs, concentrations in sugars and organic acids do not depend on fruit position in the canopy. This was not the case for apples (cv. 'Aroma') which were richer in soluble solids and inverted sugars in fruits picked from outside the tree. In fact, elevated temperature in the external environment induced a net decrease in sucrose and malic acid in the fruit (Nilsson and Gustavsson, 2007).

The interior fruit ripening occurs in particular microclimate conditions (shade environment, lower temperatures and elevated moisture). The microclimate effect on quality of the fruit was verified in Citrus genus. Clementine fruit grown in Tunisia was obviously larger and heavier with a sweeter juice as the fruit is positioned in the outer of the tree (Mars et al., 1994). This was also true for Thompson navel and Maltaise and is in agreement with our findings in figs.

Solar radiation is the key factor in overall fruit crop quality (Jackson, 1989). Fruit size, firmness, soluble solids, pH and acidity were all affected by light as well in apple and peach (Proctor and Lougheed, 1976; Erez and Flore, 1986) and this was also true for figs except for soluble solids of the juice. Shading suppresses soluble solids concentration and fruit weight of apples (Seeley et al., 1980). Shading of peach trees delays harvest, increases preharvest drop, reduces soluble solids and firmness, and changes the relationship between firmness and ground colour (Marini et al., 1991). Study of pomegranate (cv. 'Gabsi') intra-tree variability showed no effect of shade conditions on fruit size and external fruit colour (Mars and Marrakchi, 2000). In general, the most quality indices influenced by light exposure include fruit size, soluble solid rates,

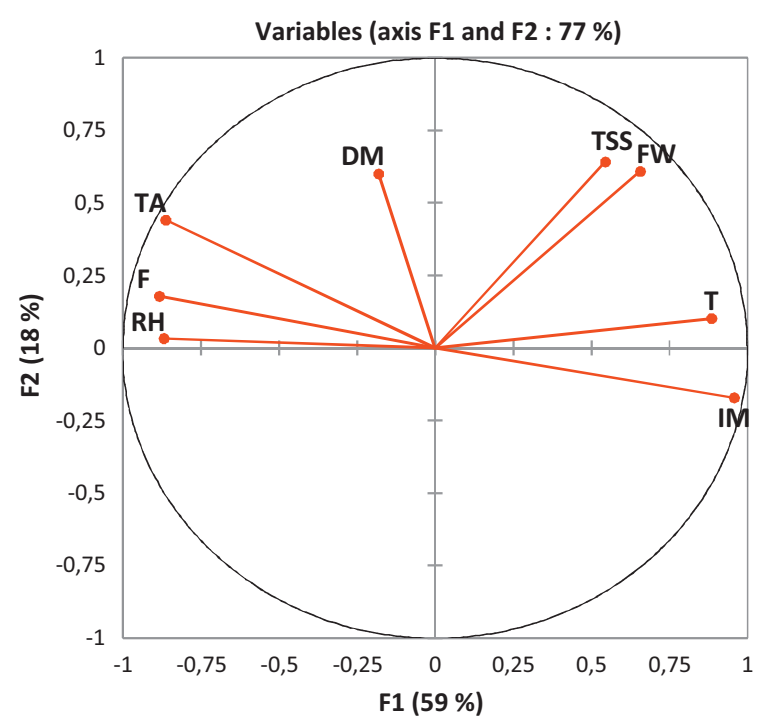

Fig. 2. Circle of correlation between climate factors and morpho-chemical parameters of 'Bouhouli' figs. DM, dry matter; F, firmness; FW, fresh weight; IM, index of maturity; $\mathrm{RH}$, relative humidity; T, temperature; TA, titratable acidity; TSS, total soluble solids. 
Version définitive du manuscrit publiée dans / Final version of the manuscript published in :

Scientia Horticulturae (2013), Vol. 162, p. 4954, DOI: 10.1016/j.scienta.2013.07.032

Journal homepage: http://www.journals.elsevier.com/scientia-horticulturae

acid rates, and surface colour (Lewallen, 2000). The development of quality parameters in figs is influenced by the amount of light in the vicinity of the receptacle during maturity.

Taste and calibre of figs changed depending on fruit position in the canopy. Figs developing underneath the foliage in the central core of the tree exhibited a lack of quality attributes. Firmness, acidity and maturity index were the most affected parameters and, as displayed in Fig. 2, were the most correlated with environmental factors. Flesh firmness is an important quality index even if soft figs have a short shelf life in the postharvest. Firmness was negatively correlated with temperature $\left(r=-0.91^{* *}\right)$. Rising temperature contributes to fig softening and acidity lowering as TA was positively correlated with firmness $\left(r=0.90^{* *}\right)$ (Fig. 2). This confirms the importance of high temperature degrees in quality of the fruit. Figs directly exposed to sunlight soften drastically and it seems evident that high temperature and exposure to sunlight speed-up ripening process. Fresh weight of the fruit was also correlated with temperature $\left(r=0.74^{*}\right)$. It becomes obvious that the higher is the temperature surrounding fig receptacle in the tree, the better is the calibre of the fruit at harvest.

\section{Conclusions}

Elevation until $800 \mathrm{~m}$ could not be a limiting factor in fig tree growing. In sub-humid climate of Tunisia, the fig can be cultivated in mountainous locations exceeding perhaps $800 \mathrm{~m}$ over the sea. The specific climate prevailing the summer prior to maturity is determinant in development of quality attributes in figs. Cultivar 'Bouhouli' yields tasteful and sumptuous fruits when grown in high-lands of 'Djebba'. Genetic and environmental interactions could be responsible of the quality of figs yielded by this cultivar in the mountain. In such areas, the fig is considered as key component of local agro-systems since long time ago. Adaptation of fig species in various bioclimates makes fig crop widespread as well in down plain or in high altitude without knock-on effect on final quality of the fruit.

Intra-tree investigations showed that quality of figs is influenced by position of the fruit in the canopy. Sun-exposed sectors of the canopy yield more fruit of higher quality than shaded inside canopy sectors. As demonstrated in the present study, the microclimate inside the tree is definitely different from the periphery. Besides photosynthesis rates, temperature and relative humidity influenced final quality of figs. Canopy management techniques are recommended to reduce shading effects on fig tree. Since tree training systems, and techniques such as winter and summer pruning and fruit thinning, can alter irradiance levels in the canopy, more knowledge in this respect could usefully be applied to increase orchard efficiency especially in fig species which information concerning such applications are still missing and pruning in general is too little mastered. Summer pruning, subject of controversy in fig tree, may be somewhat applied in the right time to improve light penetration into foliage necessary for fruit quality benefit. Removal of leaves near the fruit clusters to allow more light onto the receptacle and improve fruit quality which remains useful especially this practice was proved efficient in vineyards.

\section{Acknowledgments}

We thank farmers living in 'Thibar' and 'Djebba' for their permanent help and assistance in the orchard. Thanks are also addressed to Marielle Boge and besides, all SQPOV team for their excellent technical support in the Lab. Funding for this work was provided by the Ministry of Higher Education and Scientific Research MESRS
(UR03AGR04), Tunisia and the Agence Universitaire de la Francophonie (AUF) (Grant ref. G3-110/1649).

\section{References}

Arslan, D., Ozcan, M.M., 2011. Influence of growing area and harvest date on the organic acid composition of olive fruits from Gemlik variety. Scientia Horticulturae 130, 633-641.

Audergon, J.M., Reich, M., Souty, M., 1991. Abricots les variations des critères de qualité. Arboriculture Fruitière 416, 35-46.

Çaliskan, O., Polat, A.A., 2008. Fruit characteristics of fig cultivars and genotypes grown in Turkey. Scientia Horticulturae 115, 360-367.

Can, H.Z., 2008. Estimation of leaf area index in some Breba fig cultivars. Proceeding of the IIIrd International Symposium on fig. Acta Horticulturae 798, 109-111.

De Wit, M., Nel, P., Osthoff, G., Labuschagne, M.T., 2010. The effect of variety and location on Cactus Pear (Opuntia ficus-indica) fruit quality. Plant Foods for Human Nutrition 65, 136-145

Ercisli, S., Orhan, E., 2007. Chemical composition of white (Morus alba), red (Morus rubra) and black (Morus nigra) mulberry fruits. Food Chemistry 103 (4), 1380-1384.

Erez, A., Flore, J.A., 1986. The qualitative effect of solar radiation on 'Redhaven' peach fruit skin color. HortScience 21 (6), 1424-1426.

Fellahi, E., Simons, B.R., 1993. Influence of fruit spacing on fruit quality and mineral partitioning of 'Redchief Delicious' apple under full crop conditions. Fruit Varieties Journal 47 (3), 172-178.

Hunt, R., 1990. Basic Growth Analysis. Unwin Hyman Ltd., London.

Inglese, P., Basile, F., Schirra, M., 2002. Cactus pear fruit production. In: Nobel, P.S. (Ed.), Cacti: Biology and Uses. University of California Press, CA, USA, pp. 163-181.

IPGRI, CIHEAM, 2003. Descriptors for Fig. International Plant Genetic Resources Institute/International Centre for Advanced Mediterranean Agronomic Studies, Rome, Italy/Paris, France, 52 p.

Jackson, J.E., 1989. World-wide development of high density planting in research and practice. Acta Horticulturae 243, 17-27.

Kliewer, W.M., Smart, R.E., 1989. Canopy manipulation for optimizing vine microclimate, crop yield and composition of grapes. In: Wright, C.J. (Ed.), Manipulation of Fruiting. Butterworths, London, pp. 275-291, 414 p.

Koyuncu, F., 2004. Organic acid composition of native black mulberry fruit. Chemistry of Natural Compounds 40 (4), 367-368.

Kulina, M., Djurdjic, Z., Vico, G., 2002. Pomological traits of some once-bearing figs in the area of Trebinje. Acta Agriculturae Serbica 7 (13), 9-15

Lewallen, K.A.S., 2000. Effects of light availability and canopy position on peach fruit quality. Virginia Polytechnic Institute and State University, Blacksburg, VA, USA, May (Master of Science in Horticulture).

Lipe, W.N., Perry, R.L., 1988. Effects of rootstocks on wine grape scion vigor, yield and juice quality. HortScience 23 (2), 317-321.

Loreti, F., Morini, S., Muleo, R., Masetti, C., Vitagliano, C., 1993. Effect of solar radiation deprival on selected parameters of peach fruits. Advances in Horticultural Science 7, 105-108.

Marini, R.P., Sowers, D., Marini, M.C., 1991. Peach fruit quality is affected by shade during final swell of fruit growth. Journal of the American Society for Horticultural Science 116 (3), 383-389.

Mars, M., Abderrazak, R., Marrakchi, M., 1994. Etude de la variation intra-arbre de la qualité des fruits d'agrumes récoltés sur un même arbre I. Effets de la date de récolte, de l'orientation des fruits et de leur position dans la frondaison. Fruits 49 (4), 269-278.

Mars, M., Marrakchi, M., 2000. Etude de la variabilité intra-arbre chez le grenadier (Punica granatum L.): application à l'échantillonnage des fruits. Fruits 55, 347-355.

McPherson, E.G., Peper, P.J., 1998. Comparison of five methods for estimating leaf area index of open grown deciduous trees. Journal of Arboriculture 24 (2), $98-111$.

Melgarejo, P., Hernandez, F., Martinez, J.J., Sanchez, M.J., Salazar, D.M., 2003. Organic acids and sugars from first and second crop fig juices. Acta Horticulturae 605, 237-239.

Mousa, Y.M., Gerasopoulos, D., Metzidakis, I., Kiritsakis, A., 1999. Effect of altitude on fruit and oil quality characteristics of 'Mastoides' olives. Journal of the Science of Food and Agriculture 71 (3), 345-350.

Nilsson, T., Gustavsson, K.E., 2007. Postharvest physiology of 'Aroma' apples in relation to position on the tree. Postharvest Biology and Technology 43 (1), 36-46.

Ochoa, J.M., Leguizamón, G., Uhart, S.A., 2006. Nitrogen availability and fruit yield generation in cactus pear (Opuntia ficus-indica). IV. Effects on fruit quality. Acta Horticulturae 728, 137-144.

Ochoa, J.M., Leguizamón, G., Ortín, S.P., 2009. Quality parameters of cactus pear (Opuntia ficus-indica (L) Mill.) from two Argentinean provinces. Acta Horticulturae 811, 97-100.

Palmer, J.W., 1989. Canopy manipulation for optimum utilisation of light. Wagenmakers, P. 1991. Planting systems for fruit trees in temperate climates. Critical Reviews in Plant Sciences 10, 369-385.

Proctor, J.T.A., Lougheed, E.C., 1976. The effect of covering apples during development. HortScience 11 (2), 108-109.

Seeley, E.J., Micke, W.C., Kammereck, R., 1980. 'Delicious' apple fruit size and quality as influenced by radiant flux density in the immediate growing 
Version définitive du manuscrit publiée dans / Final version of the manuscript published in :

Scientia Horticulturae (2013), Vol. 162, p. 4954, DOI: 10.1016/j.j.scienta.2013.07.032

Journal homepage: http://www.journals.elsevier.com/scientia-horticulturae

environment. Journal of the American Society for Horticultural Science 105 (5), 645-647.

Shulman, Y., Fainberstein, L., Lavee, S., 1984. Pomegranate fruit development and maturation. Journal of Horticultural Science 59 (2), 265-274.

Smart, R.E., Dick, J.K., Gravett, I.M., Fischer, B.M., 1990. Canopy management to improve grape yield and wine quality-principles and practices. South African Journal for Enology and Viticulture 11 (1), 3-17.

Snelgar, W.P., Martin, P.J., 1997. Leaf area index and fruit size of kiwifruit. Acta Horticulturae 444, 199-204.
Snelgar, W.P., Hopkirk, G., Seelye, R.J., Martin, P.J., Manson, P.., 1998. Relationship between canopy density and fruit quality of kiwifruit. New Zealand Journal of Crop and Horticultural Science 26, 223-232.

Trad, M., Gaaliche, B., Renard, C.M.G.C., Mars, M., 2012. Quality performance of 'Smyrna' type figs grown under Mediterranean conditions of Tunisia. Journal of Ornamental and Horticultural Plants 2 (3), 139-146.

Vidaud, J., 1997. Le figuier. Monographie. Editions Centre Technique Interprofessionnel des Fruits et Légumes (Ctifl), Paris, 264 p. 